\title{
La vajilla de servicio de Esquina de Huajra (Dpto. Tumbaya, Jujuy, Argentina). Alternativas teóricas para interpretar su significado
}

RMA

Arqueología

\author{
Agustina Scaro* y María Beatriz Cremonte**
}

* CONICET- Instituto de Geología y Minería. Universidad Nacional de Jujuy. E-mail: agustina.scaro@gmail.com ** CONICET - Instituto de Geología y Minería, Facultad de Humanidades y Ciencias Sociales. Universidad Nacional de Jujuy. E-mail: cremontebeatriz@gmail.com

\begin{abstract}
Resumen
En este trabajo se explora el significado de la vajilla cerámica de servicio procedente del asentamiento HumahuacaInca de Esquina de Huajra. Se analizaron las propiedades de adecuación y restricción de los recipientes para un uso dado y la contigüidad o relación espacial de las vasijas entre sí y con otros elementos de la cultura material. Asimismo, se intentaron detectar redes asociativas significantes (iconicidad) entre los diferentes elementos de un contexto dado. Se estudió una muestra conformada por 10 vasijas enteras o parcialmente fragmentadas y 94 fragmentos de la Terraza 1 y de la Terraza 3, los de este último como integrantes de ajuares mortuorios y de un área restringida adyacente. A partir de las características morfológicas, decorativas y de manufactura se discute el significado de la vajilla de servicio y el comportamiento diferencial de estilos alfareros locales y no locales en relación con el consumo de bienes de prestigio, con la realización de algunas prácticas sociales y como probables indicadores de género y de origen étnico.
\end{abstract}

Palabras claves: Quebrada de Humahuaca; cerámica; Humahuaca-Inca; vajilla de servicio; significado.

Serving Vessels of Esquina de Huajra (Tumbaya, Jujuy, Argentina). Theoretical Alternatives for Interpreting Their Meaning

\begin{abstract}
In this paper, the meaning of ceramic serving vessels from the Humahuaca-Inca settlement Esquina de Huajra is explored. Affordances and constraints properties for a given use and the contiguity or spatial relation of the vessels with each other and with other material culture elements were analyzed. The presence of significant associative networks (iconicity) among the different elements in a given context was also investigated. A sample of 10 complete and partially fragmented vessels and 94 sherds from Terraza 1 and Terraza 3 was analyzed, the latter integrating grave offerings and an adjacent restricted area. From the morphologic, decorative and manufacturing characteristics, the meaning of serving vessels and the differential behavior of local and non-local pottery styles are discussed as indicators of gender and ethnic origin and in relation to prestige goods consumption and social practices performance.
\end{abstract}

Keywords: Quebrada de Humahuaca; pottery; Humahuaca-Inca; serving vessels; meaning.

Nuevos enfoques de la Arqueología en el estudio de la materialidad consideran a la cultura material como un elemento activo en las prácticas sociales y proponen comprender su significado en relación con el contexto de producción, consumo y circulación de los bienes, pero también con las ideas y las actividades humanas a partir de las cuales se genera su significado. En el marco de dichas propuestas, este trabajo tiene como objetivo avanzar en la comprensión del significado de las vasijas de servicio en las Terrazas 1 y 3 del sitio incaico Esquina de Huajra (Tumbaya, Jujuy), poniendo a prueba algunos conceptos de la Arqueología Cognitiva.

En esta primer etapa sólo consideramos a la vajilla de servicio, entendida como aquellas piezas no restringidas de fácil acceso, cuyo tamaño corresponde a porciones individuales o grupales (Rice 1987). Hemos elegido a esta categoría de alfarería porque se trata de objetos con un amplio despliegue visual de diseños pintados, que presentan diferentes tratamientos de las superficies y porque aparecen en altos porcentajes debido a la frecuencia de su uso y reemplazo en contextos tanto públicos como privados.

Los estudios en el asentamiento Esquina de Huajra se iniciaron hace más de una década como resultado de las tareas de rescate realizadas debido al inminente ensanchamiento de la Ruta Nacional $N^{\circ}$ 9. Las excavaciones permitieron recuperar un registro arqueológico de características relevantes para el estudio de los procesos 
sociales que tuvieron lugar durante el período Incaico en el sector centro-sur de la Quebrada de Humahuaca. Los análisis cerámicos incluyeron estudios morfológicos, decorativos y de pastas, a los mismos se sumaron los resultados obtenidos de los estudios de diversos elementos de la cultura material (artefactos metálicos, elementos líticos, restos óseos humanos de las tumbas excavadas y de fauna), realizados por especialistas (Angiorama 2003, 2004; Chaparro 2004; Chaparro y Avalos 2006; Mengoni Goñalons 2005, 2007).

\section{Perspectiva Teórica}

En estas páginas se analizan las vasijas de servicio halladas en el sitio Humahuaca-Inca Esquina de Huajra, en el marco de la Arqueología Cognitiva, concibiendo a esta como una teoría interdisciplinaria de la cultura material (Knapett $2002,2005,2008$ ) que incluye a la ciencia cognitiva, la Semiótica Pragmática (Peirce 1932), la Agencia Material (Gell 1998) y los enfoques de redes (Latour 2007; Olsen 2003). La decisión de aplicar esta perspectiva surgió ante la necesidad de contar con un marco conceptual donde integrar los análisis contextuales, morfo-decorativos y aspectos de la manufactura de las vasijas cerámicas. En este sentido, el enfoque que se pone en práctica se agrega a otros recientemente planteados para el estudio cerámico del noroeste argentino (Bugliani 2010; Laguens y Pazzarelli 2011; Lazzari 2005) que pretenden indagar el significado de los objetos a partir de la co-dependencia entre mente, acción y materia, inherente a la cultura material.

La Arqueología Cognitiva trata sobre el origen y desarrollo de la conducta simbólica humana a lo largo de su proceso evolutivo, apoyándose en diversas disciplinas relacionadas, como la Psicología, la Biología evolutiva, la Sociología y la Lingüística (Rivera 2002).

Para entender los procesos por medio de los cuales los objetos cobran vida social, la perspectiva delineada propone que tanto las actividades diarias como los objetos cotidianos pueden ser socialmente significativos, enfocándose en un aspecto más amplio de la vida social que va más allá de "lo simbólico", considerando que no solamente los artefactos o bienes vistos como especiales, estéticos o mágicos son los que poseen significado. En el marco de esta propuesta, para el caso de la cerámica de servicio de Esquina de Huajra se exploraron los conceptos de adecuaciones y restricciones (affordances y constraints), de contigüidad (que forma parte del concepto más amplio de indexicalidad) y de iconicidad, planteados por Knappett $(2002,2005)$.

Las nociones de affordances y constraints permiten incluir en el análisis las adecuaciones y restricciones de los objetos para un uso dado, es decir su rango de posibilidades de uso. Dichas nociones están relacionadas con las características físicas del objeto, pero también con cuestiones culturales y lógicas de quien lo utiliza. Ello considerando que, como plantea Olsen (2003), el mundo material posee cualidades reales que afectan y modelan nuestra percepción de él. Si bien los enfoques clásicos morfo-funcionales consideran que las características formales y tecnológicas de las vasijas permiten algunos usos prácticos y dificultan otros (Rice 1987), el enfoque aquí abordado difiere de aquellas posiciones en que el análisis se focaliza en las interrelaciones entre mente, agencia y materialidad que se entrelazan en el objeto.

El concepto de indexicalidad, que como ya se dijo incluye al de contigüidad, se deriva de la definición de Índice de Peirce (1932), tomado de la Semiótica. Este índice corresponde a un signo que está en relación espacio-temporal, de contigüidad o de causalidad con su referente. Para entender estos conceptos debemos considerar que la producción de un signo no responde necesariamente a un intento de comunicar un mensaje por medio del lenguaje, sino que a menudo es una acción práctica que ocurre en el mundo material. De esta manera, el significado de un objeto cerámico podrá ser comprendido en relación a las vinculaciones espaciales que presenta con otras vasijas cerámicas y también con otros elementos de la cultura material, vale decir el contexto en el que se encuentra.

Por último nos referiremos a la iconicidad, entendiendo al Ícono como un signo que representa a su referente por medio de la similitud (Knappett 2005), por ejemplo cuando se establecen semejanzas entre objetos confeccionados con diferentes materias primas. Estas similitudes en los registros arqueológicos son del orden visual, aunque en otros casos pueden ser también olfativas, auditivas o táctiles.

En el análisis de las vasijas de servicio de Esquina de Huajra, se aplicaron las variables de tamaño (diámetro de abertura, diámetro máximo y altura total), espesor de las paredes, tratamiento y acabado de las superficies, en relación con las nociones de affordances y constraints. En el análisis de la contigüidad hemos considerado las vinculaciones espaciales de los elementos cerámicos y no cerámicos que integran cada contexto. Finalmente, en relación con el concepto de iconicidad, buscamos identificar conexiones icónicas o "redes asociativas" entre diversos elementos cerámicos y no cerámicos de acuerdo a sus similitudes, considerando que estas asociaciones incluirían tanto a la materialidad, como a ideas y actividades involucradas, aproximándonos al significado que habrían tenido las vasijas de servicio de Esquina de Huajra.

\section{Breve caracterización del asentamiento Esquina de Huajra}

Esquina de Huajra ha sido definido como un asentamiento Humahuaca-Inca (Cremonte et al. 2006-2007) ubicado en 


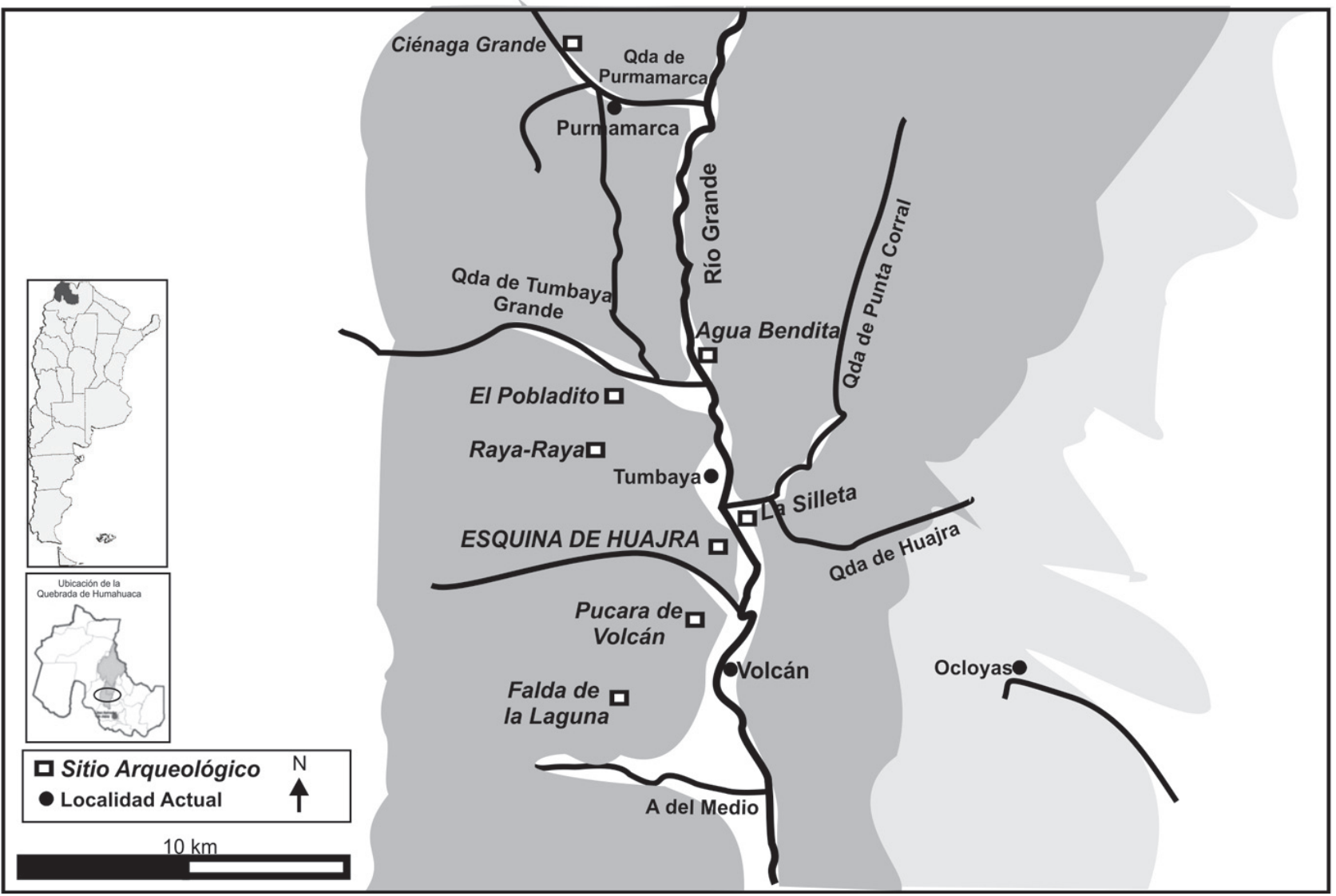

Figura 1. Localización de los sitios del sector centro-sur de la Quebrada de Humahuaca.

Figure 1. Location of south-central sector of Quebrada de Humahuaca sites.

la curva de Huajra, en el sector centro-sur de la Quebrada de Humahuaca, entre el actual pueblo de Tumbaya y el poblado prehispánico Pucara de Volcán. El asentamiento está estratégicamente emplazado frente a la quebrada de Huajra, uno de los accesos directos más importantes hacia los valles orientales (Figura 1).

Las estructuras se construyeron sobre los faldeos medio e inferior de un cerro, a 1.990 msnm. Las mismas son poco visibles ya que fueron cubiertas por el acarreo y depositación de sedimentos. Esta situación favoreció la preservación del sitio, pero dificulta conocer la superficie total construida, sus características arquitectónicas y la configuración espacial.

Hasta el momento se excavaron $222 \mathrm{~m}^{2}$ en el faldeo medio de la ladera este, identificándose dos niveles horizontalizados próximos. Uno inferior, denominado Terraza 1, en el que se encontró parte de un recinto rectangular de ángulos rectos con un pequeño vano rectangular de cuidada construcción en su muro sur. El otro sector horizontalizado (Terraza 3) conformaría un área de enterratorio. Allí se excavaron hasta ahora cuatro entierros que muestran variaciones en las técnicas constructivas, en las modalidades de inhumación y en los acompañamientos mortuorios. Entre los entierros se destacan las Tumbas 1, 2 y 3 que fueron construidas sobre el piso de ocupación y no en cámaras subterráneas en el interior de viviendas, como es lo usual en la Quebrada de Humahuaca. La Tumba 4 se corresponde con el patrón inhumatorio local, tratándose del entierro en urna de dos sub-adultos (Cremonte y Gheggi 2011).

Las recientes calibraciones de los nueve fechados obtenidos en carbón vegetal y material óseo humano (Cremonte y Gheggi 2011) indican que Esquina de Huajra correspondería fundamentalmente a una ocupación tardía, acotada a un lapso entre 1.500 y el 1.580 D.C. (Greco com. pers.). Esta cronología remite al período Hispano-Indígena, sin embargo, en Esquina de Huajra no se han hallado elementos españoles. Se trata de un contexto claramente Humahuaca-Inca que no muestra los rasgos típicos que caracterizan a los conjuntos ya históricos, marcando diferencias por ejemplo, con el cementerio de La Falda de Tilcara (Bordach 2006, Bordach et al. 1998). La abundancia y diversidad de manufacturas alfareras no locales es otra característica relevante, que plantea interrogantes sobre la conformación poblacional de sus habitantes y sobre redes de interacción, especialmente con las tierras altas.

\section{El conjunto cerámico estudiado}

El universo cerámico recuperado en Esquina de Huajra 


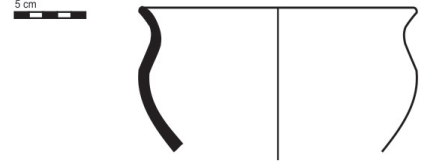

a.

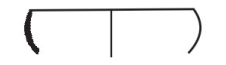

b. Puco Rojo Bruñido

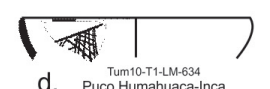

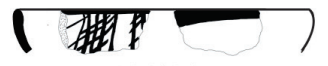

C. Puco Humahuaca-In-Inca

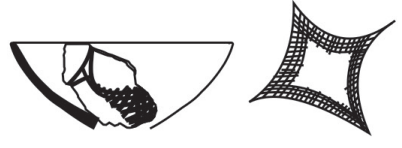

e. Tum10-T1-C24-LM-275657575152767
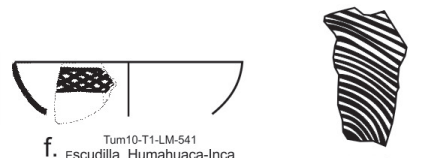

g. Escudili-a Humahuac2-20a-In

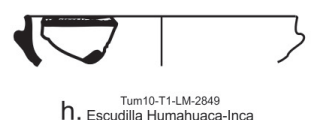

h. Escudilila Humahuacaca-Inca
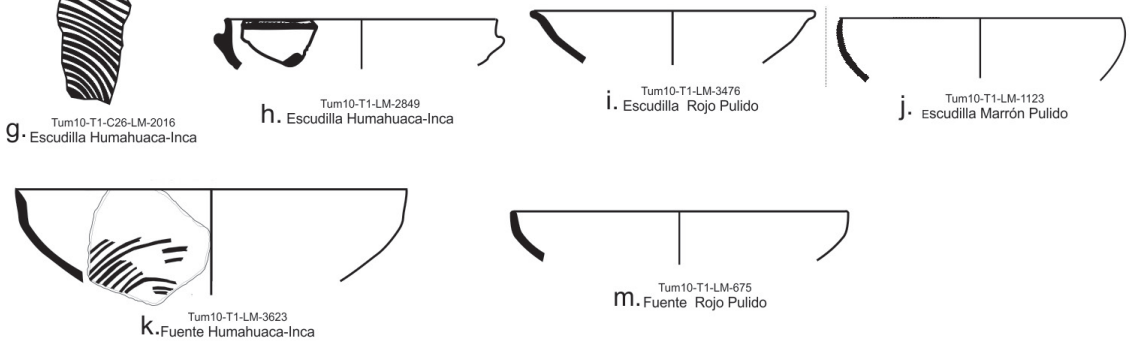

Figura 2. Vajilla de servicio de la Terraza 1.
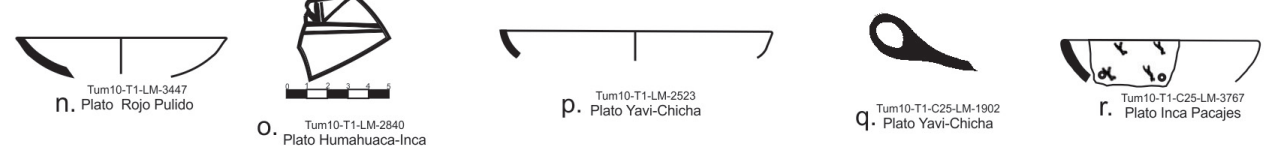

Figure 2. Service ware from Terraza 1

comprende 6.143 fragmentos y 22 vasijas enteras y parcialmente fragmentadas, procedentes del área excavada. En este trabajo, se presentan los resultados del análisis de una muestra correspondiente a las vasijas de servicio de las Terrazas 1 y 3, conformada por 10 vasijas enteras y parcialmente fragmentadas y 94 fragmentos. Se calculó un número mínimo de 91 recipientes: 47 registrados para la Terraza 1 y 44 para la Terraza 3.

Se identificaron cuatro grupos morfológicos generales para las vasijas de servicio a partir de la relación entre altura, diámetro máximo y diámetro de abertura de las piezas, los mismos incluyen pucos, escudillas, platos y fuentes (Balfet et al. 1983). El índice utilizado fue la relación entre diámetro de abertura o máximo (según se trate de pucos escudillas o platos) dividido por la altura de las piezas. Este índice brindó un valor de 1.5 a 2.5 para los pucos, 2.5 a 5 para escudillas y fuentes y $\geq 5$ para los platos. En los casos analizados, los pucos presentan un diámetro de abertura de 8 a $20 \mathrm{~cm}$, y una altura estimada de 6,5 a $12 \mathrm{~cm}$; las escudillas tienen un diámetro de abertura de 12 a $23 \mathrm{~cm}$ y una altura de 4 a $8 \mathrm{~cm}$; los platos tienen un diámetro máximo de 12 a $20 \mathrm{~cm}$ y una altura de 2,5 a $4 \mathrm{~cm}$. En el caso de las fuentes, si bien los valores del índice son iguales a los de las escudillas, sus mayores dimensiones reflejarían un consumo grupal, por lo que fueron separadas en otro grupo morfológico. Las fuentes analizadas presentan un diámetro de abertura de 24 a $36 \mathrm{~cm}$ y una altura estimada de 6 a $8 \mathrm{~cm}$.

A partir de la presencia de puntos de perfil, fue posible establecer diferentes contornos (Shepard 1985) que

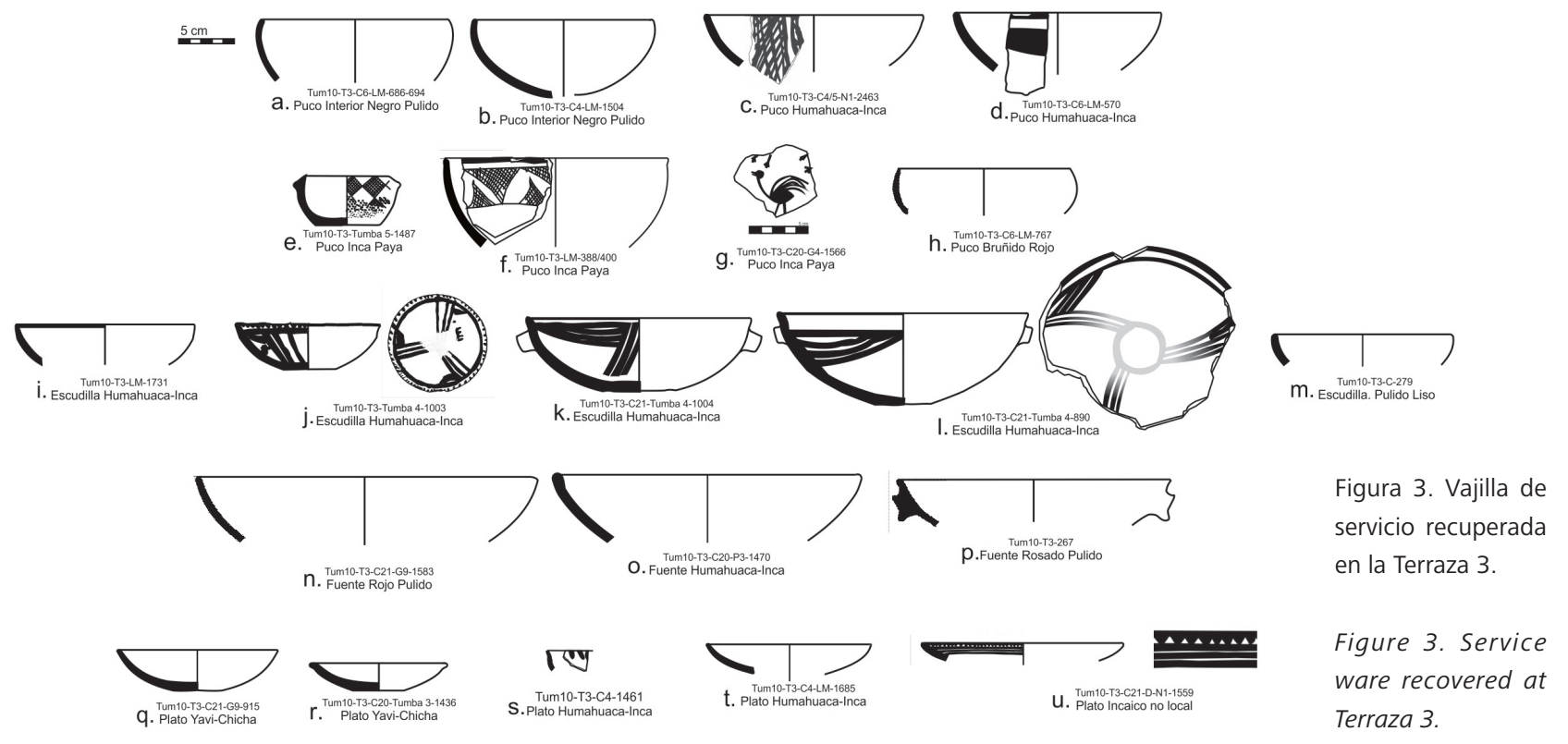




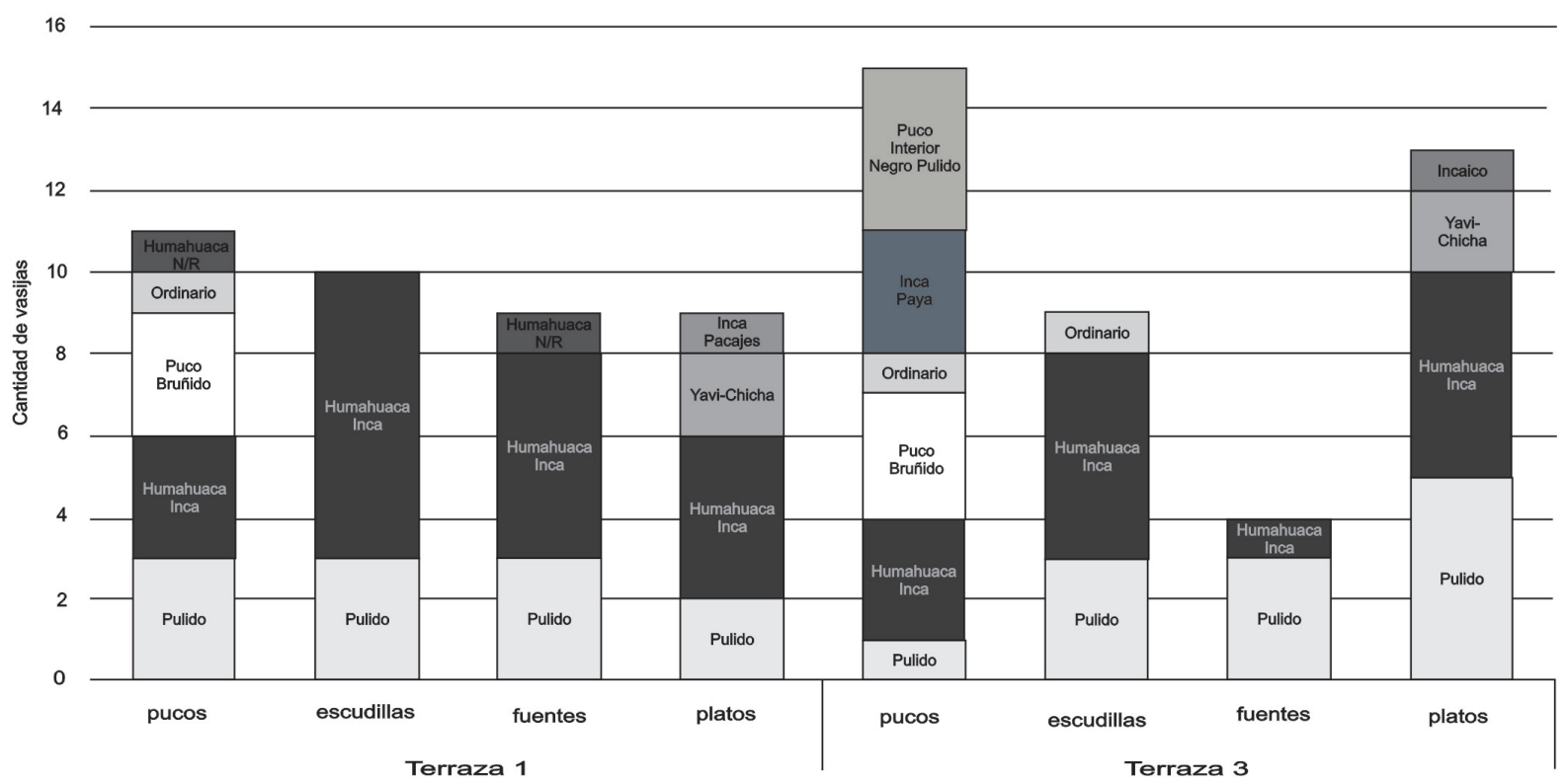

Figura 4. Número de vasijas de servicio para cada una de las categorías morfológicas de la Terraza 1 y de la Terraza 3 según las diferentes modalidades cerámicas.

Figure 4. Number of vessels of service for each of the morphological categories of Terraza 1 and Terraza 3 according to ceramics arrangements.

permitieron identificar variedades para cada grupo morfológico. El $90.9 \%$ de los pucos presentan un contorno simple, principalmente con borde directo divergente y recto (Figura 2c, 2d, 3c y $3 d$ ), algunas variedades presentan un punto de tangencia vertical que genera un borde invertido (Figura 2b, 3a, 3b, 3e y 3h); el $9.1 \%$ restante muestra contorno inflexo con borde directo o evertido (Figura 2a). Las escudillas son también principalmente de contorno simple $(65.2 \%)$ de borde directo o ligeramente invertido (Figura $2 \mathrm{f}, 2 \mathrm{j}$, 3i y $3 \mathrm{~m}$ ) y en menor medida de contorno inflexo (34.8\%) con borde directo o muy evertido (Figura $2 \mathrm{~h}$ y $2 \mathrm{j}$ ). Las fuentes son de contorno simple (Figura 3n y 3o) (66.6\%) e inflexo (Figura $3 p)(33.3 \%)$ con borde directo y evertido y de paredes rectas divergentes y curvas. Finalmente, la mayoría de los platos presentan un contorno simple (71.4\%) con borde directo (Figura 2n, 2p, 2r, 3q, 3t y 3u) y en menor medida son de contorno inflexo (28.6\%) de borde directo o evertido (Figura 3r y 3s).

En el gráfico de barras de la Figura 4 puede observarse el número de vasijas para cada categoría morfológica hallada en las Terrazas 1 y 3 que, fundamentalmente corresponden a los diferentes tipos y estilos cerámicos presentes. Debe aclararse que la categoría Pulido incluye tanto a vasijas castañas $(7.5 \mathrm{YR} 3 / 3)^{1}$, rosadas (10R 4/4), negras (5YR 2.5/1) y rojas (2.5YR 4/8) sin decoración (lisas), englobando varios tipos alfareros que aún no fueron definidos. Una excepción es el Rosado Pulido Liso (10R 4/4) que se manifiesta como un tipo incaico recurrente en el sector centro-sur de la Quebrada de Humahuaca.

\footnotetext{
${ }^{1}$ Los colores están expresados según la Munsell Soil Color Charts.
}

Asimismo, en el gráfico de barras mencionado puede observarse que los pucos resultan ser más numerosos en la Terraza 3, incluyendo a los del estilo incaico regional Inca Paya, ausentes en la Terraza 1, donde la variedad de tipos y estilos es menor. Las escudillas aparecen en cantidades similares en ambas terrazas. Se observa un predominio de escudillas pulidas lisas y HumahuacaInca, respecto de lo que ocurre con otras categorías morfológicas como los pucos, que presentan una mayor variedad de tipos y estilos.

Los platos y las fuentes muestran las mayores diferencias en cuanto a su popularidad. En la Terraza 3 los platos son más abundantes y presentan un mayor despliegue de decoraciones y formas. Por su parte, las fuentes son más comunes y más variadas en la Terraza 1. Además, mientras que estas últimas pueden ser de superficies pulidas o alisadas, en el sector funerario todas las fuentes presentan superficies pulidas.

En la Figura 2 se ilustra la variabilidad completa de formas y decoraciones de la vajilla de servicio recuperada en la Terraza 1. Los dos pucos castaños pulidos lisos (7.5YR 3/3) presentan formas y tamaños similares, mientras que el Rosado Pulido Liso (10R 4/4) (Figura 2a) es más grande y su perfil es inflexionado, tratándose de una forma única. Dentro de esta categoría, una mención especial merecen los Pucos Bruñidos (Figura 2b) rojos (5R 3/3), castaños (7.5YR 3/2) o negros (7.5YR 2.5/1) en ambas superficies o que combinan dos de estos colores en cada superficie o aún en una sola (rojo y castaño en la superficie externa). Estos pucos parecen ser resultado de una producción 
estandarizada ya que son todos sub-elípticos de 12 a $14 \mathrm{~cm}$ de diámetro de abertura y $70 \mathrm{~mm}$ de altura, presentan bordes levemente invertidos y las bases que han podido registrase son siempre planas. A simple vista las pastas son finas, de color castaño oscuro o gris con numerosas y pequeñas inclusiones claras que contrastan en la matriz arcillosa (Cremonte y Solís 1998). El estudio petrográfico de las mismas en secciones delgadas permitió identificar que en su mayoría corresponden a litoclastos de dacita, andesita o granodiorita hornbléndica. Estas características y el análisis composicional por ICP realizado (con determinación de 45 elementos traza) indican que no habrían sido producidos localmente en la Quebrada de Humahuaca. A su vez, por microscopía electrónica (SEM y EDS) y por Difracción de Rayos $X$ pudo determinarse que el bruñido de las superficies, de una intensidad tal que a veces adopta el aspecto de "espejado" se debió a un tratamiento mecánico sin agregado de resinas ni engobes especiales (Cremonte y Botto 2009). Se trata de recipientes excepcionales y de excelente manufactura que conforman un tipo alfarero definido.

Los pucos Humahuaca-Inca de la Terraza 1 se caracterizan por sus diseños negros de trazos finos, elaborados en las superficies internas rojas (10R 4/6) o castañas (7.5YR 3/3), siempre pulidas. Este estilo se deriva del Humahuaca Negro sobre Rojo, presente en toda la Quebrada desde el Período de Desarrollos Regionales y que se caracteriza por una vajilla predominantemente alisada y pintada con registros de trazo grueso (Cremonte y Solís 1998). Los registros decorativos presentes en los mismos corresponden a bandas reticuladas horizontales o verticales (Figura 2c y 2d) asociadas a línea negra sobre el labio. Es común que los reticulados sean de malla cerrada, patrón característico del momento incaico. Otro motivo de este estilo son las guirnaldas reticuladas en línea fina asociadas a línea negra sobre el labio (Figura 2e). Se hallaron también algunos fragmentos pulido lisos negros que podrían corresponder a Pucos Interior Negro Pulido, pero al no ser posible identificar la forma no fueron considerados.

Las escudillas decoradas de la Terraza 1 (Humahuaca-Inca) muestran en general bandas horizontales reticuladas de línea fina, asociadas o no al labio pintado de negro (Figura 2f), círculos concéntricos en línea fina (Figura 2g), así como líneas negras solas tal como se observa en la Figura 2h, pieza que se diferencia por presentar dos asitas laterales macizas. Las piezas no decoradas son escasas y presentan superficies pulidas rojas (2.YR 4/8) o castañas (7.5YR 4/3) (Figura 2i y 2j). La escudilla roja pulida de la Figura 2i presenta una forma muy particular, caracterizada por un perfil inflexionado que la individualiza dentro de la vajilla de servicio.

Se registraron fuentes decoradas de los estilos Humahuaca Negro sobre Rojo y Humahuaca-Inca, los elementos decorativos asociados con el primero corresponden a círculos concéntricos (Figura 2k), mientras que los motivos correspondientes al Humahuaca-Inca presentes en esta forma incluyen una única línea gruesa paralela al borde, bandas horizontales reticuladas en línea media y a una guarda de líneas gruesas paralelas. En menor medida se registraron fragmentos de fuentes sin decoración de superficies rosadas (10R 4/4) o rojas (2.5YR 4/8) pulidas (Figura 2l).

Finalmente, los platos hallados en la Terraza 1 son, como ya mencionamos, menos numerosos que los presentes en la Terraza 3. Las piezas de manufactura local que no están decoradas presentan sus superficies rojas (2.5YR 4/8) o castañas (7.5YR 3/3) pulidas (Figura $2 \mathrm{~m}$ ). Asimismo, se hallaron tres ejemplares Humahuaca-Inca que presentan una guarda seguramente vertical con diseños de líneas rectas mostrando motivos geométricos de línea muy fina, típicamente incaicos (Figura 2n), así como una cabeza de ave modelada, propia de los platos ornitomorfos incaicos. Las piezas de manufactura no local incluyen un plato de perfil simple con engobe morado (Figura 20) y otro con asa lateral y línea negra fina sobre el labio (Figura $2 p)$, ambos del estilo Yavi-Chicha, así como un plato del estilo Inca Pacajes, con el diseño típico de llamitas en la superficie interna (Figura 2q).

La vajilla de servicio hallada en la Terraza 3 incluye Pucos Interior Negro Pulido (Figura 3a y 3b) de perfiles simples, con bordes levemente invertidos y bases pequeñas. Las superficies internas de estos pucos son muy pulidas y su exterior puede ser ordinario o alisado con engobe rojo. Los pucos decorados del estilo Humahuaca-Inca en general son hemisféricos y presentan un perfil simple, su decoración incluye el labio pintado de negro asociado a dos motivos reticulados paralelos en línea fina (Figura 3c) y un motivo geométrico poco discernible, integrado por una línea negra fina sobre el labio y otra más gruesa en el borde interno (Figura 3d). Asimismo, se han identificado pucos del estilo Inca Paya, decorados con rombos reticulados de línea fina en la superficie externa² (Figura $3 e)$, triángulos reticulados alternados en línea fina en el interior (Figura 3f) y el motivo del suri, también en la superficie interna (Figura 3g); en todos los casos las piezas son pulidas. El Puco Bruñido de la Figura 3h presenta su superficie externa bicolor roja y castaña.

Las escudillas halladas en el sector funerario (Terraza 3) están en su mayoría decoradas, y corresponden al estilo Humahuaca-Inca. El registro de los diseños incluye líneas negras pintadas sobre el labio que pueden aparecer solas (Figura 3i) o asociadas a otras cortas paralelas ubicadas en el borde interno. Se destacan tres escudillas halladas en la Tumba 4, se trata de dos grandes escudillas "gemelas", ya que presentan formas y decoraciones semejantes, y de una escudilla entera pequeña, de forma similar y con muy

\footnotetext{
${ }^{2}$ El puco ilustrado fue hallado en una tumba disturbada ubicada fuera del área excavada. Sin embargo, fue considerada en este análisis debido a la singularidad de su decoración y características de manufactura.
} 


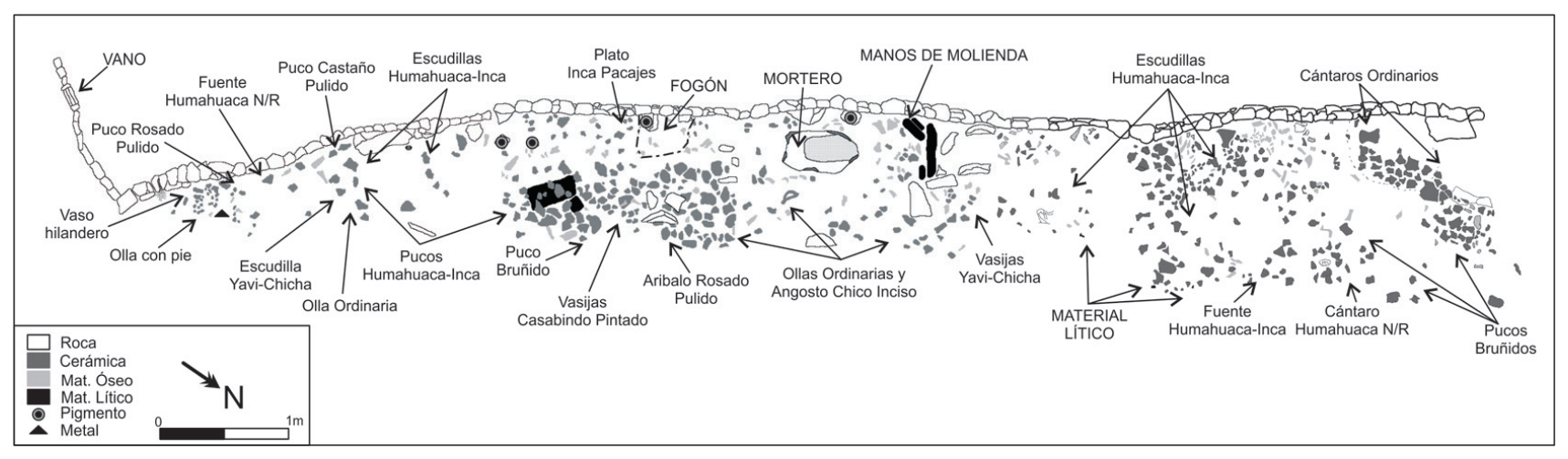

Figura 5. Planta de la Terraza 1, indicando la ubicación de los hallazgos

Figure 5. Terraza 1 map, indicating the location of the findings

\section{Discusión y síntesis}

La morfología y decoración de la vajilla de servicio de las Terrazas 1 y 3 de Esquina de Huajra, combinadas con algunas características de manufactura representadas en sus pastas, han permitido poner a prueba las categorías de adecuaciones (affordances), restricciones (constraints), contigüidad e iconicidad con el fin de indagar el significado de las vasijas en ambos sectores.

Adecuación, restricciones y contigüidad de la vajilla de servicio en la Terraza 1

En primer lugar y en relación con la Terraza 1 (Figura 5), para el concepto de contigüidad se consideraron las asociaciones espaciales de las vasijas cerámicas entre sí y con otros elementos del registro arqueológico. En este sector se vinculan espacialmente pucos Bruñidos, Humahuaca-Inca y pulidos sin decoración. Asimismo, están presentes las escudillas Humahuaca-Inca de superficies pulidas, así como las escudillas lisas pulidas; las Yavi-Chicha y aquellas Humahuaca Negro sobre Rojo, pero en menor proporción. Por otro lado, registramos algunas fuentes decoradas y no decoradas, en su mayoría pulidas. En cerámica local pulida y no decorada aparecen los platitos, así como aquellos con motivos geométricos en línea muy fina; y por último platitos de manufactura no local, correspondientes a los estilos Yavi-Chicha e Inca Pacajes.

La vajilla de servicio descripta se encuentra en asociación directa con ollas de diversos tamaños (ordinarias y Angosto Chico Inciso), aríbalos Rosados Pulidos, cántaros ordinarios o decorados, y vasijas no locales Casabindo Pintado (Albeck 2001) y Yavi-Chicha, procedentes de la Puna jujeña.

Como puede observarse en la Figura 5, en el sector correspondiente a la esquina del recinto se encontraron fragmentos de vasijas de servicio junto a un vasito hilandero y un tortero decorado en negro sobre rojo (elaborado a partir de un fragmento re-utilizado), y a una olla ordinaria con pie de manufactura no local. La olla con pie es una forma incaica excepcional en la Quebrada 
de Humahuaca; de acuerdo a su perfil, y en relación a la tipología realizada por Marchegiani (2011), el espécimen de Huajra corresponde a una vasija del momento Inca y no de fases más tardías.

En cuanto a la contigüidad con elementos no cerámicos, en la Terraza 1, la vajilla de servicio está asociada espacialmente a un fogón de planta irregular. Cerca de esta estructura de combustión se hallaron un gran mortero con su una mano de moler y pequeños morteros. Asimismo, se recuperaron abundantes huesos de mamíferos y de aves, así como una espátula fragmentada y una aguja, ambos de hueso. Los restos óseos (Mengoni Goñalons 2005) corresponden en su mayoría a camélidos (guanacos, llamas y en menor medida vicuñas), representados sobre todo por las partes medias y distales de las patas y las costillas y en menor medida huesos del cráneo y de miembros de cérvidos. Resulta interesante la presencia de llamas de gran tamaño, consideradas como "cargueras". Los huesos de aves son menos abundantes, aunque muestran una gama variada de partes anatómicas, indicando que pudieron integrar la dieta y/o ser utilizadas para la obtención de plumas. Los elementos líticos están también presentes en este entramado de objetos de la Terraza 1, se trata de 12 instrumentos, 18 desechos de talla y dos núcleos (Chaparro y Ávalos 2006). La casi totalidad de estos elementos son de obsidiana, aunque existen algunos de arenisca silicificada. El único objeto de metal corresponde a un cincel de bronce estañífero (Angiorama 2004) procedente de la limpieza del muro en el sector que cierra en ángulo recto.

Respecto de las adecuaciones y restricciones de la vajilla de servicio para un uso dado (affordances y constraints), en la Terraza 1 los pucos presentan paredes delgadas (de
3,5 a $6 \mathrm{~mm}$ ) y sus tamaños (diámetros y altura) indicarían un consumo individual probablemente de alimentos líquidos, por sus superficies impermeables debido al pulido. Los platos, de paredes un poco más gruesas que los pucos (de 4 a $7 \mathrm{~mm}$ ), también tienen en todos los casos superficies pulidas. Su poca profundidad los hace más propicios para el consumo de alimentos sólidos, tal vez carne, un alimento muy apreciado y de consumo restringido en momentos incaicos, como fue planteado por Bray (2003). Los platos permiten además exhibir su contenido, es decir que los comensales podían visualizar quienes consumían determinadas calidades de alimentos. De esta manera, se establece una relación de indexicalidad por la contigüidad entre plato y alimento especial y a la vez una red asociativa entre la actividad de comer, el alimento y el recipiente. Por su parte, tanto fuentes como escudillas son en su mayoría pulidas. Las escudillas, de paredes más gruesas (de 4 a $9 \mathrm{~mm}$ ) se relacionarían al consumo individual de alimentos semilíquidos o sólidos, mientras que las fuentes, de paredes de espesor medio (de 4 a $7 \mathrm{~mm}$ ) se vinculan a un consumo grupal.

\section{Adecuación, restricciones y contigüidad de la vajilla de servicio en el sector funerario}

En la Terraza 3 y tal como se observa en la Figura 6, se combina el espacio cerrado de las tumbas y sus equipos mortuorios, con otro externo, restringido pero abierto, al cual consideramos destinado a los rituales mortuorios.

En el espacio externo a las tumbas, se asocian los Pucos Bruñidos, los pucos del estilo Inca Paya y otros de superficies pulidas, decorados y sin decoración. Asimismo, se registraron escudillas en todos los casos pulidas, y algunas con decoración pintada, así como
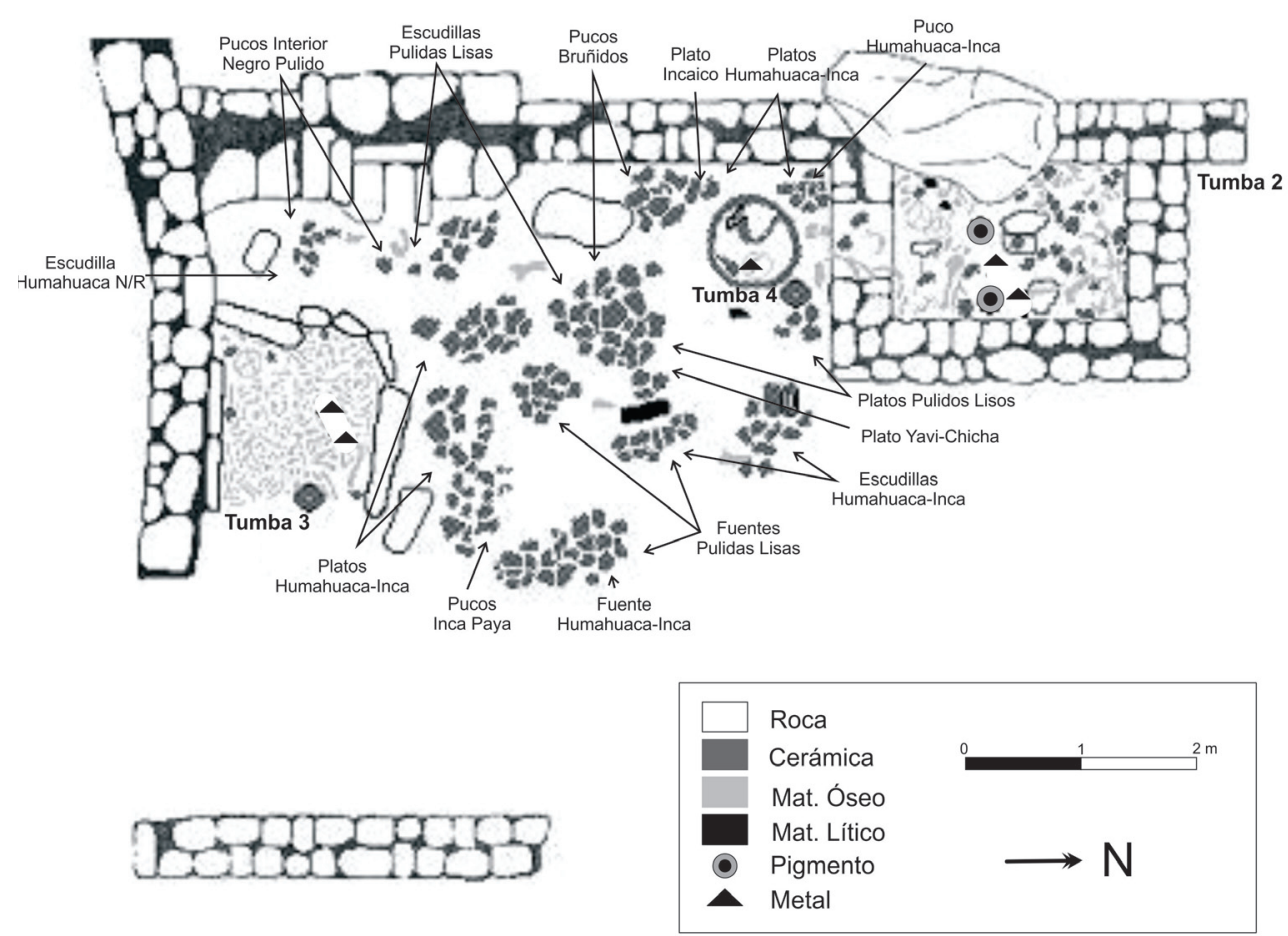

Figura 6. Croquis del sector norte de la Terraza 3 con la ubicación de las vasijas de servicio recuperadas.

Figure 6. Sketch of the northern sector of Terraza 3 with the location of the serving vessels found. 
fuentes también pulidas. Al igual que en la Terraza 1, están presentes platos pulidos decorados y lisos, así como platitos Yavi-Chicha, además se halló un ejemplar no local finamente decorado.

En el espacio que venimos describiendo de la Terraza 3, la vajilla de servicio aparece en asociación directa con diez ollas Angosto Chico Inciso y dos ordinarias, cuatro aríbalos pulidos lisos y dos decorados, seis cántaros ordinarios, cinco Humahuaca Negro sobre Rojo y dos HumahuacaInca; seis vasijas Casabindo Pintado y una Yavi-Chicha, así como dos vasijas pulidas lisas, una alisada con engobe rojo y diez ordinarias. Asimismo, se registraron al menos cinco vasijas ordinarias grandes restringidas, probablemente utilizadas para trasladar bebidas (¿chicha?) y alimentos sólidos o semisólidos a este espacio desde las unidades domésticas.

En cuanto a los elementos no cerámicos, se halló un cuchillo de bronce estañífero, una pieza de cobre nativo de forma no identificable y cinco fragmentos de mineral de cobre, así como 15 instrumentos líticos, 12 desechos de talla y tres probables adornos líticos. Estos probables adornos corresponden a dos fragmentos de mica con un orificio central cada uno.

Al considerar las adecuaciones y restricciones de la vajilla para un uso dado (affordances y constraints), en la Terraza 3 se observa que los pucos pulidos y de paredes más gruesas (de 5 a $8 \mathrm{~mm}$ ) son más comunes que en la Terraza 1, indicando un consumo individual de alimentos líquidos pero por parte de individuos que se habrían congregado en eventos rituales vinculados con el entierro. Los platitos (cuyas paredes tienen un espesor de 4 a 6 $\mathrm{mm}$ ), también más abundantes y variados, indicarían un comportamiento similar pero para el consumo de alimentos sólidos. Las escudillas presentan un espesor de paredes de 5 a $7 \mathrm{~mm}$ y son aptas para el consumo individual de alimentos semilíquidos, mientras que las fuentes (cuyas paredes tienen un espesor de 4 a $8 \mathrm{~mm}$ ) son apropiadas para el consumo grupal. Ambas categorías están también presentes en este sector, cumpliendo una función similar a la planteada para los pucos.

En función de los objetivos de este trabajo, hemos considerado solamente los contextos de las Tumbas 2, 3 y 4 por presentar una cronología similar (Tumba 2: 280 \pm 50 Beta 206919, Cal $1 \delta$ 1514-1798 D.C., Cal $2 \delta$ 1495-1951 D.C. - Tumba 3: 320 \pm 50 Beta 32576, Cal $1 \delta$ 1505-1652 D.C., Cal $2 \delta$ 1464-1797 D.C. - Tumba 4: 360 \pm 40 Beta 255446, Cal $1 \delta$ 1464-1628 D.C., Cal $2 \delta 1450-1635$ D.C. $\left.{ }^{3}\right)$. La Tumba 1, un entierro múltiple en cámara mortuoria similar a la de la Tumba 2, presentaba un ajuar cerámico muy escaso y fragmentado y el fechado realizado sobre hueso humano la ubica a principios del Siglo XV, razones

\footnotetext{
3 Los fechados fueron calibrados con el programa OxCal v4.1.6 (Bronk Ramsey 2009) y se utilizó la curva de calibración ShCal04 (McCormac et al. 2004).
}

por las cuales no fue considerada en esta oportunidad.

La Tumba 2 corresponde al entierro secundario de siete individuos en una estructura de planta rectangular y muros dobles rellenos. La cerámica es escasa y en general muy fragmentada. La vajilla de servicio corresponde a un Puco Interior Negro Pulido y a dos escudillas rojas, una de ellas alisada y la otra pulida. Estas piezas están vinculadas a cuatro vasijas ordinarias grandes, una de la cuales presenta hollín en el exterior, y a una vasija decorada Humahuaca Negro sobre Rojo. Es probable que estos pocos fragmentos cerámicos sean los restos de las vasijas ubicadas como ajuar en la inhumación primaria.

Además de la cerámica, integraban el acompañamiento mortuorio 83 cuentas muy pequeñas de hueso, dos cuentas trapezoidales blancas y otras dos cilíndricas más pequeñas, una verde y la otra negra, una pinza de depilar, un colgante de bronce estañifero y polvos de distintos colores: azul (azurita), verde (atacamita) y amarillo (oropimente). Asimismo, se hallaron dos cráneos de pato criollo (Cairina Moschata s.p., Tonni com. pers.), sin duda elementos de alto valor simbólico, teniendo en cuenta que el pato en época incaica ha sido reiteradamente representado, como por ejemplo en los platos ornitomorfos. En nuestro caso sería una especie presente en el "paleolago Volcán-Tumbaya" que se extendía desde el Arroyo del Medio hasta Tumbaya (Solís y Rivero 1994) y que es mencionado en las fuentes históricas ${ }^{4}$. Además y como ya fue mencionado, evidencias de consumo de aves se han encontrado en los conjuntos zoofaunísticos de la Terraza 1.

En distintos sitios de la Quebrada de Humahuaca se hallaron cráneos de animales incluidos a modo de ajuar en tumbas, como ocurre en el cementerio Hispano-Indígena de La Falda de Tilcara (Bordach 2006). Allí, en los rasgos 11, 13 y 19 se descubrieron huesos de pavita de monte (Cracidae Penelope) como ofrenda de un hombre y de una mujer respectivamente, y dentro de una jarra; mientras que en los rasgos 20 y 25 se hallaron huesos de ave no identificada. Otro caso es el del Pucara de Tilcara, donde fue hallado un esqueleto de cóndor dentro de una cámara cilíndrica (Yacimiento 63). Asimismo, en el Yacimiento 202, fueron hallados huesos de ave acompañando los restos de cinco adultos y de un niño inhumados dentro de una construcción de planta rectangular. Por su parte, en el Yacimiento 7 se registraron seis cráneos de puma en el interior de un cántaro decorado que formaba parte del ajuar de un entierro (Debenedetti 1930).

La Tumba 3 corresponde a una estructura semicircular utilizada para inhumar a una mujer de aproximadamente 40 años. Las vasijas de servicio registradas en el ajuar incluyen un platito entero negro pulido Yavi-Chicha, un Puco Interior Negro Pulido, una escudilla Humahuaca-

\footnotetext{
${ }^{4}$ Archivo de Tribunales de Jujuy. "Información de Juan Ochoa de Zárate" Carpeta n¹, fs. 9 vuelta, año 1596.
} 
Inca decorada con una banda reticulada vertical en negro sobre fondo rojo, una fuente roja pulida con hollín en el borde y una vasija abierta de forma no determinable pulida y decorada en negro sobre rojo. Estos recipientes de servicio están asociados a dos vasijas restringidas no locales (Yavi-Chicha y Casabindo Pintado), y a otra decorada en negro sobre rojo poco pulida con hollín en su interior, indicando el probable quemado de alguna ofrenda. Respecto de los elementos no cerámicos, se hallaron huesos de camélidos y dos alfileres de metal (topu), uno de ellos de bronce estañífero y el otro de una aleación de plata y cobre. Esta aleación es poco común en el noroeste argentino, tratándose probablemente de una manufactura no local (Angiorama 2004).

La Tumba 4 consiste en el entierro primario de dos niños (un perinato de 38-40 semanas de gestación y un subadulto de 7 años \pm 24 meses) dentro de una vasija ordinaria a la que se le seccionó el cuello, probablemente para introducir a los niños en el momento del entierro. Dentro de la urna y como ajuar funerario se introdujeron dos escudillas grandes pintadas, dos aríbalos Rosados Pulidos $^{5}$, una escudilla pequeña, un cántaro decorado con banderines, todos del estilo local Humahuaca-Inca, fragmentos de unas pocas vasijas cerradas Ordinarias y de ollas Angosto Chico Inciso. Asimismo, se hallaron dos cinceles de metal y una pinza de depilar de bronce estañifero dentro de la urna.

Como ya se dijo, las dos escudillas grandes presentan la misma forma y configuración decorativa y, al igual que los dos aríbalos Rosados Pulidos, una de ellas es un poco más pequeña que la otra (Figura $3 \mathrm{k}$ y $3 \mathrm{I}$ ). La otra escudilla más pequeña, de forma y configuración decorativa similar, presenta el motivo de "peine", propio del estilo Inca Paya (Figura 3j).

\section{Redes asociativas y significado de la vajilla de servicio de Esquina de Huajra}

En relación con lo que venimos describiendo, en la Terraza 1, la contigüidad de elementos cerámicos y no cerámicos y las adecuaciones de las vasijas de servicio halladas permiten plantear que se trataría de un área doméstica, correspondiente probablemente al patio de una vivienda. Allí existiría un sector que habría estado directamente destinado a la preparación (procesamiento y cocción), almacenaje temporario y consumo de alimentos, vinculado al fogón, a los instrumentos de molienda, a los restos de camélidos y a las ollas y cántaros, así como a la vajilla de servicio hallada. Estas actividades se habrían realizado en el sector central de la Terraza 1 (Figura 5). La presencia del vasito hilandero con su tortero indican actividades domésticas como el hilado, y la presencia

\footnotetext{
5 En este trabajo, el término aríbalo es equivalente al de aribaloide, por tratarse de cántaros de manufactura local con atributos morfológicos y decorativos que los diferencian de los típicos cántaros incaicos cuzqueños.
}

de núcleos de obsidiana y desechos de talla indican que se habrían llevado a cabo tareas de reducción para la obtención de formas base de instrumentos líticos, siendo posible que los núcleos hayan ingresado al asentamiento con alguna preparación inicial mínima o sin procesamiento previo. Los análisis de Activación Neutrónica realizados por Chaparro (Chaparro y Ávalos 2006) sobre algunos instrumentos de obsidiana arrojaron resultados similares a los de la fuente de Zapaleri, en la Puna Jujeña, a la de Laguna Blanca (Reserva Eduardo Avaroa, Sud Lípez, Bolivia), así como a la de Alto Tocamar (San Antonio de los Cobres), indicando una gran dinámica en cuanto al aprovisionamiento de las materias primas.

Si consideramos al conjunto cerámico completo, resulta evidente que la olla con pie, sumada a los aríbalos y los platitos, conformarían la vajilla incaica típica de individuos relacionados con la administración estatal que viven en las provincias del imperio, como ha señalado Bray (2004). La misma autora, y en concordancia con lo hallado en este sector de Huajra, observa un aumento de las superficies pulidas sin decoración en los aríbalos hallados en los sitios de la periferia, tendencia opuesta al centro del imperio. En Huajra esto se manifiesta en la presencia de los nueve aríbalos, casi el 30\% del total de las formas cerámicas incaicas. Bray vincula esta diferencia con el interés por parte de la administración incaica de comunicar mensajes diferentes a las poblaciones de las regiones provinciales. Quizás, en nuestro caso como en otros de la periferia, esto podría deberse a que la sujeción de las poblaciones no requería de una imposición tan enfática de la ideología del imperio a través de sus íconos, representados en la decoración cerámica.

En este contexto doméstico de la Terraza 1 es notoria la incidencia de piezas foráneas a la Quebrada de Humahuaca, especialmente provenientes de las tierras altas, así como el despliegue de formas, acabados y tratamientos de superficie y pastas finas de la vajilla de servicio en este nivel. Las redes de significación en la que estarían insertas estas piezas, de la que también formarían parte elementos tales como aríbalos pulidos lisos y ollas con pie, referirían a un contexto de status y de interacción, permitiendo plantear a Esquina de Huajra como un asentamiento estratégico y especial.

En la Terraza 3 las tres tumbas analizadas en este trabajo y el espacio externo a las mismas han funcionado como un área funeraria a partir de cuyo estudio surgen comportamientos simbólicos significativos. En el sector externo a las tumbas, la contigüidad de vasijas cerámicas con elementos no cerámicos y arquitectónicos como las Tumbas 2 y 3, señalaría que el mismo probablemente habría funcionado como un espacio restringido de congregación destinado a la preparación de las inhumaciones y sus ritos correspondientes.

Como han señalado Cremonte y Gheggi (2011), los 
sepulcros sobre elevados de la Terraza 3 corresponden a entierros secundarios, señalando probablemente un ritual comunal vinculado con la práctica de una o varias ceremonias consecutivas en relación con la manipulación de los restos de los difuntos y sus ofrendas. Es probable que esta práctica esté relacionada con el culto a los ancestros, ya que permite el acceso continuo a los restos de personas consideradas importantes en una sociedad, reflejando el papel de los antepasados en la vida, concepción vigente en el mundo andino hasta la actualidad. Las tumbas sobre elevadas conocidas son excepcionales en la Quebrada de Humahuaca, un caso son las del Complejo A de Los Amarillos (Nielsen 2006), aunque se trata de inhumaciones más tempranas que las de Esquina de Huajra.

El hecho de que los platos sean más abundantes y variados en el sector externo de la Terraza 3 que los hallados en el sector doméstico (Terraza 1), estaría reflejando el consumo individual de alimentos sólidos en un contexto público ceremonial. Las escudillas y fuentes halladas en este sector externo presentan en la mayoría de los casos superficies pulidas, indicando que se habría seleccionado la vajilla de servicio de mejor terminación para ser consumida en este contexto. La recurrencia de las superficies pulidas, tanto en escudillas como en pucos, así como el mayor número de estos últimos probablemente estén relacionados con un mayor consumo de líquidos en este sector debido a la impermeabilidad de las paredes de estas piezas.

Por otro lado, la presencia de pucos Inca Paya resulta relevante si se considera que piezas de este estilo habrían sido distribuidas como bienes de prestigio en los centros estatales del noroeste argentino. De acuerdo a Williams (2005), estos bienes habrían circulado en canales paralelos a los de la cerámica Inca Imperial, junto con alfarería Yavi Chico Policromo e Inca Pacajes. La amplia distribución del Inca Paya indicaría prestigio y alto valor de circulación, sugiriendo que los Incas habrían valorado los estilos cerámicos de ciertos grupos étnicos de la región. La presencia de Inca Paya probablemente de manufactura local en Esquina de Huajra podría estar indicando la asimilación de este estilo, así como el rol de estas vasijas, similar al de la cerámica cuzqueña, ausente en Huajra y tan escasamente representada en los sitios del noroeste argentino.

En cuanto a los acompañamientos mortuorios, el ajuar de la Tumba 2 resulta significativo por el peso simbólico que habrían tenido los adornos, los polvos de colores y los cráneos de los dos patos. La escasa presencia de alfarería y su grado de fragmentación permite pensar que serían restos de las vasijas ofrendadas en la inhumación primaria, las cuales más tarde y con la manipulación de los restos de los difuntos, probablemente en uno o más rituales, se habrían fracturado, siendo reemplazadas por otros elementos.
La contigüidad de los elementos que integran la inhumación de la mujer de la Tumba 3 reflejaría distinciones de género y de identidad étnica o social. Los topu presentes son símbolos claramente femeninos en el Incaico y hasta el momento colonial temprano, sirviendo como indicadores de género. El hecho de que por lo menos uno de los topu no sería de manufactura local (aleación de plata y cobre) y la presencia de vasijas Yavi-Chicha y Casabindo Pintado procedentes de las tierras altas permiten pensar que la mujer inhumada en esta tumba sería oriunda de la Puna occidental jujeña o bien que mantenía fuertes vínculos con esta zona.

Los elementos del ajuar de la Tumba 4 expresan la dualidad andina, que como sabemos se manifiesta en diferentes aspectos organizativos de esta sociedad (Cereceda 1988; Duviols 1977; González 1998). En este caso, se trata de dos niños, uno de aproximadamente siete años y el otro recién nacido, inhumados junto a dos escudillas, dos aríbalos y dos cinceles. El hecho de que todos ellos sean también uno más grande y uno más pequeño, nos hace pensar en que existe una correlación entre la mayor o menor edad de los niños y el tamaño de los objetos que componen el ajuar. En este sentido, se podría establecer una red de significados entre los niños, las escudillas, los aríbalos y los cinceles. Los mismos estarían expresando la cosmovisión dual del grupo de pertenencia de los niños como prácticas sociales que pueden manifestarse en distintas circunstancias y diversas materialidades.

Otro tipo de redes asociativas o conexiones icónicas se pueden establecer con los Pucos Bruñidos. Cremonte y Botto (2009) han caracterizado a estas vasijas como piezas sub-elípticas pequeñas, estandarizadas y de excelente manufactura, cuyas superficies rojas, negras o castañas están bruñidas al punto de adoptar en ocasiones un aspecto espejado, y que mojadas reflejan la luz con un brillo similar al de las piezas de metal. Los Pucos Bruñidos son excepcionales en el noroeste argentino y las características de sus pastas los distinguen de los estilos cerámicos locales y foráneos conocidos para la Quebrada de Humahuaca. Los contextos fechados indicarían que estas piezas excepcionales aparecerían alrededor del siglo XIV (período Intermedio Tardío) y que serían más populares durante la época de dominación incaica. Consideramos que los Pucos Bruñidos han ejercido una atracción en el observador más allá de lo estético. Probablemente habrían sido utilizadas en contextos de alta visibilidad, públicos o domésticos, pero de estatus. En relación con ello, es posible incluirlos dentro de lo que Gell (1992) ha denominado tecnología del encantamiento, haciendo referencia a objetos que tienen el poder de encantarnos o hechizarnos, poder que proviene de la destreza técnica necesaria para producirlos.

A partir de la decoración interna pintada en negro que presenta la vajilla de servicio, se plantean algunas consideraciones sobre el contexto de consumo e 
identidad. En un contexto de comensalidad, estas configuraciones decorativas y los posibles mensajes que inscriben son develados al consumir alimentos o bebidas. En este sentido, a la satisfacción de consumir un alimento se suma el deleite estético de descubrir la decoración, situación que asimismo evoca diversas ideas y mensajes políticos, ideológicos e identitarios. Por otra parte, hemos registrado la presencia recurrente de un motivo decorativo, la banda reticulada, presente no sólo en las vasijas de servicio, sino también en las de almacenamiento y cocción. Este diseño parece ser una expresión de la identidad social de los grupos que habitaron el sector Centro-Sur de la Quebrada de Humahuaca.

Otras redes asociativas o icónicas pueden establecerse incluyendo la dimensión tecnológica de las pastas, considerando, como lo manifestara Lechtman (1977), que la misma no está determinada sólo por las características ambientales sino que abarca un conjunto de elecciones sociales, económicamente e ideológicamente significativas. Por ello, focalizarse en la forma y/o decoración de un objeto, ignorando las técnicas y los procesos que lo produjeron, impide comprender su completo significado social (Peelo 2011). La caracterización petrográfica de 73 secciones delgadas de vasijas de servicio y de almacenaje/preparación de alimentos de Esquina de Huajra (no incluida en este trabajo) permitió identificar 7 Grupos y 25 variedades reflejando, en comparación con otros asentamientos de la Quebrada de Humahuaca, un repertorio muy amplio de pastas (Cremonte et al. 2008). El análisis de las pastas permitió establecer que la alfarería local de la Quebrada de Humahuaca refleja una tradición tecnológica de manufactura basada en el agregado de fragmentos más o menos angulosos de filitas y pizarras de la Formación Puncoviscana, comportamiento que se mantiene desde el Formativo (Cremonte et al. 2007). Sin embargo, se manifiesta una correlación entre determinadas texturas de las pastas y algunos tratamientos y acabados de la superficie. Asimismo, este análisis ha permitido identificar aquellas alfarerías no locales, las cuales indican vínculos con las tierras altas (Puna de Jujuy y probablemente borde de la Puna salteña y altiplano sur de Bolivia). Estas vasijas no locales corresponden a dos grandes grupos tecnológicos de pastas: 1) las de tradición Yavi-Chicha con abundantes inclusiones blancas redondeadas de sedimentitas alteradas (Cremonte 2011) y 2) aquellas con clastos de volcanitas. Así, por ejemplo, hemos registrado basalto y dacitas en algunos pucos Inca Paya (Figura 3e), andesitas y/o dacitas en los Pucos Bruñidos (Figura 2b y $3 \mathrm{~h}$ ), traquitas en el plato Inca Pacajes de la Terraza 1 (Figura 2r) y basalto en el platito de la Terraza 3 (Figura $3 u)$, todos ellos indicando diferentes procedencias.

En cuanto a la distribución de las variedades de pastas de la vajilla de servicio, podemos concluir que en la Terraza 1 estos contenedores son en su mayoría de manufactura local. Los no locales corresponden a Pucos Bruñidos e Inca
Pacajes, así como a pucos y escudillas castaños pulidos de pastas muy finas. En este contexto, llama la atención la popularidad de recipientes de servicio no locales de manufactura fina. En el sector funerario de la Terraza 3 también están presentes casi todas las variedades de las pastas locales del Grupo 1. Sin embargo, la cerámica Yavi-Chicha con sus características inclusiones blancas es más abundante que en la Terraza 1 y, si bien la proporción de cerámica no local con componentes volcánicos es similar, es menor la cantidad de pucos, escudillas y platos de pastas muy finas. La presencia de alfarerías de manufactura no local y de pastas finas indicarían un consumo de prestigio y redes sociales que en Esquina de Huajra remiten a diversas áreas, algunas de ellas muy distantes. El despliegue de acabados de superficie de las vasijas de servicio, así como la parafernalia funeraria en Esquina de Huajra muestra una distinción en relación a otros contextos contemporáneos, como el Pucara de Volcán. Esta situación es similar a la observada en el valle del Mississipi por Pauketat y Emerson (1991) y podría indicar que, al igual que para el caso de la alfarería Ramey Incisa, las vasijas de Esquina de Huajra serían un elemento activo en el discurso socio-ideológico de un grupo de élite en situaciones públicas o privadas.

Por último, resulta importante destacar que a partir de este estudio petrográfico se ha podido determinar que los pucos del estilo incaico regional Inca Paya se manifiestan tanto de manufactura local como alóctona. Tal es el caso del puco ilustrado en la Figura $3 f$ que presenta una pasta local. Por su parte, la pasta del fragmento de un puco encontrado en el interior de una tumba disturbada externa al área excavada (Figura 3e), presenta abundantes fragmentos de volcanitas, indicando una manufactura no local. Estas diferencias son congruentes con lo observado a nivel iconográfico, donde en algunas vasijas se registró una integración del estilo Inca Paya al Humahuaca-Inca, reflejando como alternativas, ya sea la presencia de probables mitmaqkuna que produjeron en Huajra su cerámica, o bien la asimilación de íconos Inca Paya por parte de los alfareros quebradeños.

Para concluir, el análisis de la vajilla de servicio hallada en Esquina de Huajra en el marco de la propuesta abordada, parte de la idea de que no sólo los objetos considerados como "especiales" operan como símbolos sociales importantes, sino también los objetos cotidianos. A partir de las categorías consideradas fue posible avanzar en los probables significados que emergen de las relaciones formales, decorativas y de manufactura, junto con las espaciales y asociativas de la vajilla de servicio entre sí y con otros elementos del registro arqueológico en cada uno de los contextos estudiados. De esta manera, la propuesta abordada contribuye a comprender la variación de significados de la materialidad según sus contextos de uso y consumo

San Salvador de Jujuy, 20 de Marzo 2012 


\section{Agradecimientos}

Para esta investigación se utilizaron fondos de los subsidios otorgados a los proyectos PIP CONICET 0060 y ANPCYT PICT 01538. Agradecemos la colaboración de la geóloga Alba Díaz del Instituto de Geología y Minería de la UNJu y a los alumnos de la carrera de Antropología Mariana Benavidez, Fabiola Vilte y Daniel Ochoa, quienes colaboraron en la confección de las fichas de registro y en el dibujo de la cerámica. Por último, a la Comunidad Aborigen de Tumbaya por el apoyo brindado a las investigaciones y por su interés en la cerámica arqueológica como expresión de su identidad.

\section{Bibliografía}

Albeck M. 2001. La Puna argentina en los períodos Medio y Tardío. E. Berberián, A. Nielsen (eds.), Historia Argentina Prehispánica (tomo I), cap. 9, pp. 347-388, Ed. Brujas, Córdoba.

Angiorama, C. I. 2003. "Producción y circulación de objetos de metal en la Quebrada de Humahuaca en momentos prehispánicos tardíos (900 - 1535 d. c.)". Facultad de Ciencias Naturales-Instituto Miguel Lillo, Universidad Nacional de Tucumán, Argentina, 105 pp. MS.

Angiorama, C. I. 2004. Estudio de los objetos metálicos procedentes de Esquina de Huajra (Quebrada de Humahuaca, Jujuy), Informe, MS.

Balfet, H., M. Fauvet Berthelot y S. Monzon. 1983. Pour la normalisation de la description des poteries. Ed. Centre National de la Recherche Scientifique, Paris.

Bordach, M. 2006. Interacciones étnicas e indicadores de desigualdad social en el Cementerio de La Falda (SJTil 43), Tilcara, Jujuy. Estudios Atacameños 31: 115-128.

Bordach, M., O. Mendonça, M. Ruiz y M. Albeck. 1998. El joven señor de La Falda: indicadores de una Persona Social en el Tilcara Hispanoindígena. B. Cremonte (comp.), Los desarrollos locales y sus territorios. Arqueología del NOA y sur de Bolivia, cap. 8, pp. 199-222. EdiUnju, Jujuy.

Bray, T. 2003. To dine splendidly. Imperial pottery, commensal politics and the Inca state. T. Bray (ed.), The archaeology and politics of food and feasting in early states and empires, cap. 5, pp. 93-142, Kluwer Academic/ Plenum Publishers, New York.

Bray, T. 2004. La alfarería imperial Inka: una comparación entre la cerámica estatal del área de Cuzco y la cerámica de las provincias. Chungara, 36 (2): 365-374.

Bronk Ramsey, Ch. 2009. Bayesian analysis of radiocarbon dates. Radiocarbon 51 (1): 337-360.
Bugliani, F. 2010. Códigos estéticos, expresiones plásticas y modos de representación en la cerámica del Formativo en Yutopián (Valle del Cajón, Noroeste argentino). Revista del Museo de Antropología, 3: 21-32.

Chaparro, G. 2004. El material lítico de Esquina de Huajra-Jujuy. Informe, MS.

Chaparro G., J. Ávalos. 2006. Tecnología Lítica durante la ocupación Inka en la Quebrada de Humahuaca (Provincia de Jujuy, Argentina). P. Escola, S. Hocsman (eds.) Artefactos Líticos, Movilidad y Funcionalidad de Sitios en Sudamérica. Problemas y Perspectivas, International BAR Series. En prensa.

Cereceda, V. 1988. Aproximaciones a una estética andina: de la Belleza al Tinku. X Albó (ed.), Raíces de América. El mundo Aymara, cap. 6, pp. 283-355, Ed. Alianza/ Unesco, Madrid.

Cremonte, M. B. 2011. El estilo cerámico Yavi-Chicha en instalaciones incaicas del Noroeste Argentino. Las pastas como posible marcador identitario. Boletín del IFEA. En Prensa.

Cremonte M. B., I. Botto. 2009. Unas vasijas especiales de contextos tardíos del Noroeste Argentino. Manufactura de los "Pucos Bruñidos". Estudios Atacameños, 37: 6377.

Cremonte, M. B., S. Gheggi. 2011. Espacios rituales y cultura material en un sitio arqueológico HumahuacaInca (Quebrada de Humahuaca, Jujuy, Argentina). Revista Española de Antropología Americana. En Prensa.

Cremonte, M. B., N. Solís. 1998. La cerámica del Pucara de Volcán: variaciones locales y evidencias de interacción. B. Cremonte (comp.), Los desarrollos locales y sus territorios. Arqueología del NOA y sur de Bolivia, cap. 6, pp. 155-178. EdiUnju, Jujuy.

Cremonte, M. B., S. M. Peralta y A. Scaro. 2006-2007. Esquina de Huajra (Tum 10, Dpto. Tumbaya, Jujuy) y el poblamiento prehispánico tardío en el sur de la Quebrada de Humahuaca. Cuadernos del INAPL, 21: 27-38.

Cremonte, M. B., A. Ramírez y S. Peralta. 2007. Identificación y caracterización de manufacturas cerámicas no locales del Pukara de Volcán. Petrografía de pastas y fluorescencia de rayos. B. Cremonte y N. Ratto (eds.), Cerámicas arqueológicas. Perspectivas arqueométricas para su análisis e interpretación, cap. 4, pp. 49-71, EdiUnju, Jujuy.

Cremonte, M. B., A. Ramírez y S. Peralta. 2008. Petrografía de pastas cerámicas de Esquina de Huajra (Tumbaya, Jujuy). Las razones de su diversidad y consumo. Cuadernos, 34, Suplemento IX Jornadas Regionales de 
Investigacion en Humanidades y Ciencias Sociales: 91-92.

Debenedetti, S. 1930. Las ruinas del pucará. Tilcara, Quebrada de Humahuaca (Provincia de Jujuy).Archivos del Museo Etnográfico, 11 (Primera parte): 1- 142.

Duviols, P. 1977. Los nombres quechua de Viracocha, supuesto "Dios Creador"de los evangelizadores. Allpanchis, 10: 53-65.

Gell, A. 1992. The technology of enchantment and the enchantment of technology. J. Coote, A. Shelton (eds.), Anthropology, art and aesthetics, cap. 2, pp. 40-63, Clarendon Press, Oxford.

Gell, A. 1998. Art and Agency: Towards a new anthropological theory. Clarendon Press, Oxford.

González, A. 1998. La cultura de La Aguada. Arqueología y diseños. Filmediciones Valero, Buenos Aires.

Knappett, C. 2002. Photographs, skeuomorphs and marionettes: Some thoughts on mind, agency and object. Journal of Material Culture, 7:97-117.

Knappett, C. 2005. Thinking through Material Culture. University of Pennsylvania Press, Philadelphia.

Knappett, C. 2008. The neglected networks of material agency: Artefacts, pictures and texts. C. Knappett, L. Malafouris (eds.), Material agency. Towards a nonanthropocentric approach, cap. 8, pp. 139-159. springer. New York.

Laguens A., F. Pazzarelli. 2011. ¿Manufactura, uso y descarte? O acerca del entramado social de los objetos cerámicos. Revista del Museo de Antropología, 4: 113126.

Latour, B. 2007. Nunca fuimos modernos. Ensayo de antropología simétrica. Ed. Siglo XXI, Argentina.

Lazzari, M. 2005. The Texture of Things: Objects, People, and Landscape in Northwest Argentina (First Millennium A.D.). L. Meskell (ed.), Archaeologies of Materiality, cap. 6, pp. 126-161.

Letchman, H. 1977. Style in technology: some early thoughts. R. Merrill, H. Merril (eds.), Material Culture: Styles, Organization, and Dinamycs of Technology, cap. 1, pp. 3-21. West Publishing, St Paul, Minnesota.

Marchegiani, M. 2011. "Las formaciones sociales de Yocavil durante la dominación Inca y la conquista española. Contacto, conflicto, persistencia y transformaciones (Siglo XV-XVII D.C.)" Facultad de
Filosofía y Letras, Universidad de Buenos Aires, 399 pp.

McCormac, F., A. Hogg, P. Blackwell, C. Buck, T. Higham y P. Reimer. 2004. SHCal04 Southern Hemisphere calibration, 0-11.0 cal kyr BP. Radiocarbon 46 (3): 10871092.

Mengoni Goñalons, G. 2005. Análisis Arqueofaunístico de Esquina de Huajra: Informe preliminar. Informe, MS.

Mengoni Goñalons, G. 2007. Camelid management during Inca times in N.W. Argentina: models and archaeozoological indicators. Anthropozoologica 42 (2): 129-141.

Nielsen, A. 2006. Plazas para los antepasados: descentralización y poder corporativo en las formaciones políticas preincaicas de los Andes circumpuneños. Estudios Atacameños, 31: 63-89.

Olsen, B. 2003. Material culture after text: Remembering things. Norwegian Archaeological Review, 36 (2): 87-104.

Pauketat T., T. Emerson. 1991. The Ideology of Authority and the Power of the Pot. American Anthropologist 93 (4): 919-941.

Peelo, S. 2011. Pottery-Making in Spanish California: Creating multi-scalar Social Identity Through Daily Practice. American Antiquity 76 (4), pp 642-666.

Peirce, C. 1932. Elements of Logic, C. Hatshone, P. Weiss (comp.), Collected papers of Charles Sanders Peirce. Vol. 2. Harvard University Press, Cambridge.

Rice, P. 1987. Pottery Analysis. A sourcebook The University of Chicago Press. Chicago.

Rivera, A. 2002. "Arqueología cognitiva. Elaboración sobre un modelo psicobiológico sobre el origen y desarrollo de la conducta simbólica humana. Su aplicación en la transición del Paleolítico medio al superior". Departamento de Prehistoria de la UNED, Madrid, pp. MS.

Shepard, A. 1985. Ceramics for the archaeologist (Quinta edición). Carnegie Institution of Washington. Washington.

Solís, N. y Rivero, A. 1994 Urbanización y Riesgos Geológicos en la Localidad de Volcán - Provincia de Jujuy. Rep. Argentina. Actas III Simposio Latinoamericano sobre Riesgos Geológicos Urbanísticos: 271-278.

Williams, V. 2005. Poder y cultura material bajo el dominio Inka. Pacarina, 4: 35-68. 